\title{
Research on taxation policies that promote enterprise technological innovation in the context of big data
}

\author{
Chunxiao Zhu' ${ }^{1}$ Jiaqi $\mathrm{Zhu}^{2}$ \\ ${ }^{1}$ Financial department Linyi University Linyi, Shandong \\ ${ }^{2}$ Taxation department Shandong University of Finance and Economics Jinan, Shandong
}

\begin{abstract}
Technological innovation is the source of economic growth and the source and driving force of enterprise development. The scientific research and development of enterprises is not only beneficial to the company, but can also drive the rapid development of related industrial chains. At present, most companies in China are facing the dilemma of financing difficulties, thereby curbing their innovation capabilities. At this time, the government needs to introduce preferential policies for macro-control and guidance. Tax big data contains a large amount of data and information in all aspects required for tax management. The transparency, efficiency and predictability of big data provide strong technical support for tax collection and management. In order to promote enterprise innovation, the government has issued a series of preferential tax policies. This paper analyzes the mechanism of technological innovation and tax policies, combs the current tax policies in China, further explains the effects of the policies, and points out the shortcomings of the current preferential tax policies. Finally, some suggestions are put forward for reference by policy researchers.
\end{abstract}

\section{Theoretical analysis of tax preference and technological innovation}

\subsection{The impact mechanism of tax incentives on enterprise technological innovation}

Preferential taxation policies are incentives or concessions that the government gives to specific taxpayers who meet specific conditions based on certain political, economic and social development goals. It is an important means for the government to regulate the social economy.

As shown in Fig. 1, before the implementation of the preferential tax policy, the marginal cost and marginal revenue of the enterprise intersect at point a. The implementation of preferential tax policies has increased the technological innovation income of enterprises. In the figure, the marginal revenue curve MR rises to MR'. The degree of increase in the curve is related to the intensity of preferential tax policies. At this time, the equilibrium point is point $b$, the enterprise's technological innovation scale increases from point $\mathrm{Q}_{1}$ to $\mathrm{Q}_{2}$, and the income increases from $\mathrm{P}_{1}$ to $\mathrm{P}_{2}$ [1]. It can be seen that the preferential tax policies implemented by the government can expand the scale of enterprise technological innovation and increase the income of enterprises' technological innovation activities.

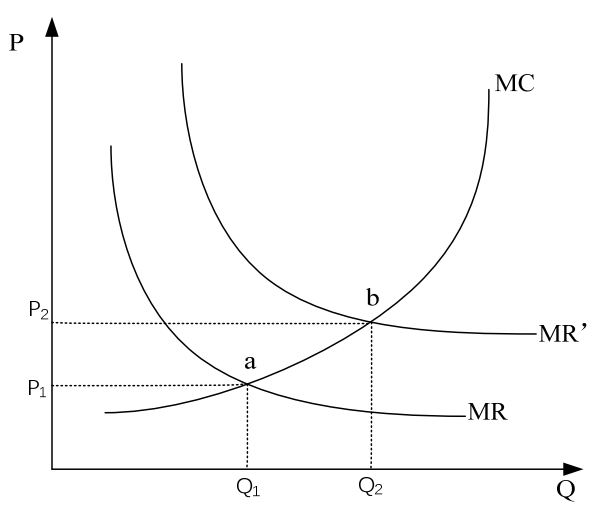

Fig 1. The impact mechanism of tax incentives on enterprise technological innovation

\subsection{Positive externalities of enterprise technological innovation}

Because of the positive economic impact of enterprise innovation activities on the external economy, there are positive externalities for technological innovation enterprises engaged in technological innovation. When scientific and technological innovation companies push their R\&D products to the market, due to the imperfect intellectual property protection system in the market, in the current big data environment, it is easy for external companies and even competitors to acquire the company's technology and then imitate it, resulting in unfair competition in the market Relationships, and even occupy new markets developed by technological innovation 
companies, making it difficult for technological innovation companies to obtain the expected economic and social benefits.

As shown in Fig. 2, due to the positive externalities of technological innovation, the social value curve is above the private value curve. When the private cost curve intersects the social value curve, from the perspective of the entire society, $\mathrm{Q}_{2}$ is the best investment scale for technological innovation. Due to the existence of positive externalities, that is, the $\mathrm{ABC}$ part of the figure, the output level of the enterprise is lower than the optimal level of the society, and the output of other social entities is excessive, which makes the efficiency of resource allocation inefficient. Therefore, the government should use a portion of the profits of other social entities to make up for the losses of technological innovation enterprises, so as to realize the optimal allocation of resources. Tax incentives are an important policy tool for the government to correct this market failure through fiscal policy. The state realizes the equalization of corporate income and social income by granting certain tax relief to high-tech enterprises. At the same time, this can encourage enterprises to research and develop new technologies and new products, and minimize the interference of the positive externalities of patented products to enterprises.

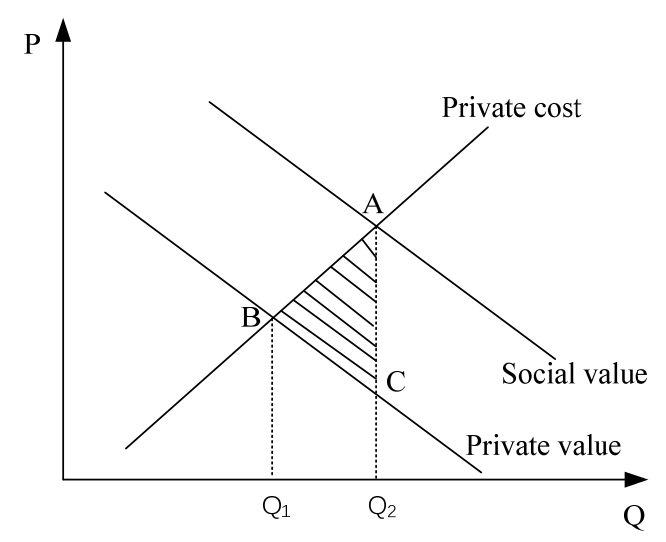

Fig 2. Analysis on the Positive Externality of Enterprise's Technological Innovation

\section{Current status of corporate R\&D under preferential tax policies}

\subsection{Preferential tax policies for enterprise technology research and development}

According to the data released on the website of the State Administration of Taxation, as of June 2019, China has successively launched 89 tax preferential policies and measures for the main links and key areas of innovation and entrepreneurship [2], covering the entire life cycle of enterprises from start-up to development. In terms of technology research and development, tax incentives are mainly reflected in the two major types of corporate income tax and value-added tax. Income tax and valueadded tax are the top two tax types in corporate taxation.

Corporate income tax is calculated by multiplying the tax rate by the balance of income minus non-taxable income, tax-free income, deductions and previous year's losses. The general corporate tax rate is $25 \%$. Therefore, the preferential policies of enterprise income tax are mainly reflected in preferential tax rates, deductions and taxes. For example, technologically advanced service companies are taxed at a reduced rate of $15 \%$ for corporate income tax; employees' education expenditures incurred by companies that do not exceed $8 \%$ of total wages and salaries are allowed to be deducted in the calculation of taxable income, and the excess is allowed in the future The tax year carry-over deduction. R\&D expenditures that do not form intangible assets are deducted $50 \%$ before tax, and those that form intangible assets are amortized at $150 \%$ before tax. High-tech enterprises can also enjoy the preferential tax policy of $15 \%$. If the enterprise's income from technology transfer does not exceed 5 million yuan, the part exceeding 5 million yuan shall be halved to the enterprise income tax.

Value-added tax preferential treatment mainly adopts preferential methods such as tax rebate, refund upon collection, and reduction or exemption. For example, if VAT exceeds the tax burden of animation enterprises, it will be refunded upon collection. Taxpayers engaged in technology transfer, technology development business and related technical consulting and technical services business are exempt from VAT. Imports of major technical equipment are exempt from VAT. The software industry VAT will be refunded if it exceeds the tax burden.

\subsection{R\&D of corporate technological innovation soars}

The results of the 2018 Chinese Enterprise Innovation -Survey show that nearly $41 \%$ of enterprises have innovative activities and nearly $8 \%$ have achieved comprehensive innovation; industrial enterprises have a relatively high innovation success rate, and independent research and development is the most important form of innovation; high-tech industries above designated size , with outstanding innovation ability, have a leading position in the manufacturing industry; cooperative innovation helps companies enhance market competitiveness; employee recognition of the company, high-quality talents, and internal incentives are the main factors affecting innovation success. The implementation effects of innovation policies have basically been recognized by the entrepreneurs.

According to the 2016-2018 "Statistical Analysis of the Characteristics of my country's Enterprise Innovation Activities" published by the Ministry of Science and Technology of China, this paper analyzes the number of enterprises carrying out innovation activities and the total number of enterprises. The results are shown in Table 1. The number of business activities carried out in China is gradually increasing, with an average annual increase of about 10,000 . 
Table1. Statistics on the number and proportion of enterprises carrying out innovation activities in China from 2016 to 2018

\begin{tabular}{|c|c|c|c|}
\hline & $\mathbf{2 0 1 6}$ & $\mathbf{2 0 1 7}$ & $\mathbf{2 0 1 8}$ \\
\hline $\begin{array}{c}\text { Number of enterprises carrying out } \\
\text { innovative activities (ten thousand) }\end{array}$ & 28.4 & 29.8 & 30.8 \\
\hline Proportion of all companies (\%) & 39.1 & 39.8 & 40.8 \\
\hline
\end{tabular}

\subsection{Increase in the level of R\&D expenditure}

R\&D expenditure has become an important indicator to measure the financial strength, education level, R\&D strength, and innovation results of a country (region). $R \& D$ expenditure intensity refers to the ratio of $R \& D$ expenditure to gross domestic product (GERD/GDP), which reflects the level of R\&D expenditure in a country (region) relative to the overall social and economic activities, and is another important indicator to measure the degree of R\&D innovation. In 2017, China's R\&D expenditure totaled US\$496 billion, ranking second in the world, while its R\&D intensity was approximately $2.2 \%$ ranking 12th in the world [3].

In the context of increasing investment in scientific and technological research and development in various countries, the number of patent registrations in China has also increased. According to data from the World Intellectual Property Organization (WIPO), the number of PCT applications in China increased year by year from 2009 to 2019, and it surpassed the United States in 2019, becoming the world's number one. Fig. 3 shows the annual trend of the number of PCT applications in China and the United States during the ten years from 2009 to 2019 and their annual ratio to the total number of global applications. The gap between China and the United States is getting smaller and smaller. In 2019, the number of PCT applications in China surpassed that of the United States.

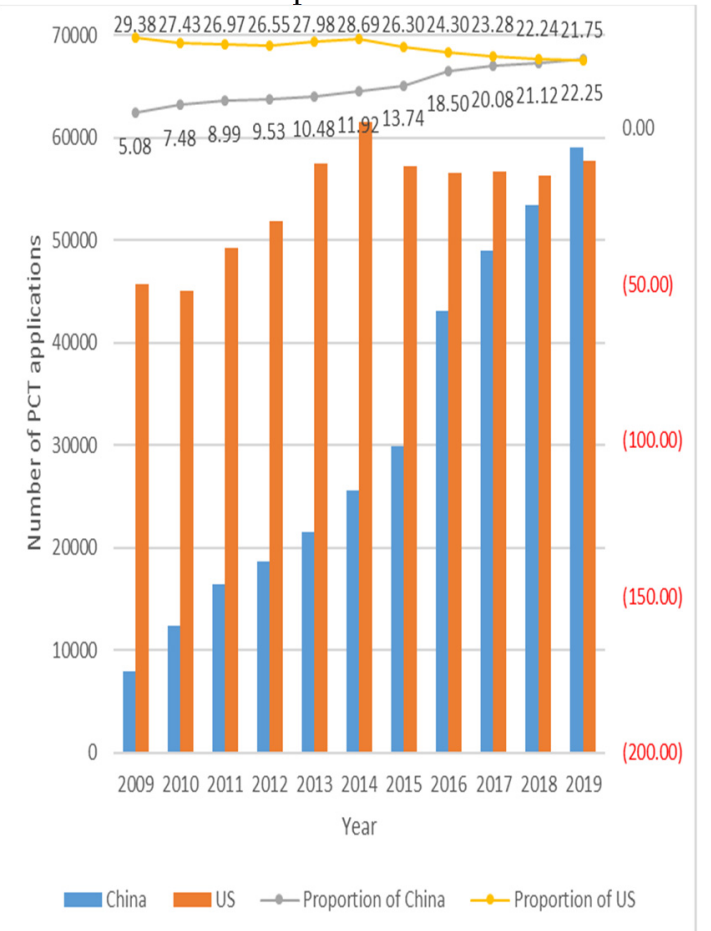

Fig 3. Annual trends and global share of PCT international patent applications of China and the US (2009-2019)[4]
The 2019 report, released by the National Bureau of Statistics on July 23, marks the 70th anniversary of the founding of the People's Republic of China on economic and social development achievements, also showed that in 2017, enterprises above the scale will enjoy tax breaks for high-tech enterprises' R\&D expenses and tax breaks. They reached 24,400 and 24,200, respectively, 3.3 times and 3.5 times that of 2009. The amount of exemption reached 57 billion yuan and 106.2 billion yuan, which played a positive role in encouraging and guiding enterprises to carry out R\&D and innovation.

\subsection{Imperfect tax big data platform}

Since preferential tax policies indirectly affect the production costs of enterprises, the degree of impact is different in the manufacturing and service industries. The adjustment cost of average unit capital and large-scale R\&D investment in the service industry have the highest level and the fastest decline year by year. The adjustment cost of the average unit capital of the manufacturing industry and the level of large-scale $\mathrm{R} \& \mathrm{D}$ investment are second only to the service industry and have the slowest decline [5].

As an emerging technology, big data is still in the early stage of development in China, and the tax big data platform has not yet been established. Lack of contact between enterprises and tax authorities, enterprises can not fully grasp the preferential tax measures, resulting in poor policy effect. Tax authorities cannot fully grasp corporate financial data, and cannot track policy effects and effectiveness in a timely manner. Although the tax policy has covered multiple industries and multiple enterprises, its effectiveness and pertinence are still lacking.

\section{Problems with current tax incentives}

\subsection{Imperfect tax system}

At present, China's taxation system lacks the law of independent innovation and development of enterprises, resulting in a lack of systematic design and overall planning of taxation systems and preferential policies, low legislative levels, imperfect systems, and insufficient policy continuity. Many policies are distributed in different tax documents, laws and regulations, and there are no reasonable standards in the implementation and judicial process. Many policies are promulgated by various state departments in the form of "notices", "decisions" and "regulations." As the various documents are independent of each other and their promulgation time varies, the implementation process is difficult, which weakens the role and effect of taxation policies.

\subsection{One-sidedness of tax policy}

The development and growth of technology companies are divided into different stages, and the current preferential policies cannot cover the entire development stage of the company, especially the initial stage of the company's 
development. In the early stages of development, most technology companies have high R\&D costs and long research processes, and the results of the research cannot guarantee success. Therefore, in the early stages, many companies are in a state of loss and tax incentives cannot be used. For example, the initial investment in the integrated circuit and software industry is very high, the risk is also high, and the return is relatively slow. In the initial stage of the enterprise, it is often in a state of loss, and it is difficult to enjoy policy preferences. For example, a software company has invested 230 million in R\&D in the past three years, and enjoys an additional deduction of 77.85 million yuan, which accounts for $34 \%$ of the total R\&D investment. However, due to the accumulated losses that have not been fully deducted, most of the actual investment in $\mathrm{R} \& \mathrm{D}$ expenses did not enjoy preferential policies [6]. And some companies have more customers. If they enjoy some tax exemption policies, they may not be able to invoice downstream companies. Under such circumstances, many companies have to abandon the tax exemption policy in order to keep customers. At the same time, these policies allow some companies to see the economic benefits and ignore the long-term nature of scientific and technological innovation, leading them to capitalize on profit and use preferential policies to conduct tax evasion and tax avoidance activities, which harms the country's economic interests.

\subsection{Enterprise's incomplete understanding of policy}

Judging from the reasons why the policy effect is not obvious or ineffective, the enterprises all believe that the policy threshold is high, the scope of application is small, the publicity is insufficient, and the awareness is low. Taking the preferential tax deduction policy for corporate R\&D expenses as an example, companies believe that the three main reasons that cause the policy to be unobvious or invalid are: ineligibility for the policy, ignorance of the policy, and cumbersome procedures.

\subsection{Strict preferential conditions and unclear regulations}

From the current situation, some preferential policies have higher thresholds, and some enterprises cannot enjoy tax incentives. For example, in the recognition of high-tech enterprises, there are 8 conditions and 4 major indicators in the latest "Administrative Measures for the Recognition of High-tech Enterprises". Many enterprises cannot meet the requirements and do not recognize the high-tech enterprises, so it is difficult to enjoy tax incentives. . Moreover, in reality, the situation of enterprises is very complicated, which is often not as obvious as the policy regulations, and the implementation of the regulations is more difficult due to the lack of detailed regulations. For example, the number of R\&D personnel is difficult to determine. Sometimes, in order to save human resources, companies often let R\&D personnel work together with other personnel, or even hold several positions.

\subsection{Weak pertinence of tax incentive for innovative talents}

Human capital is the core element to realize independent innovation of technology enterprises, and high-quality scientific and technological talents are the key to independent innovation activities of technology enterprises. At present, the preferential tax policy can not produce enough incentive effect to the scientific and technological innovation talents in scientific and technological enterprises. The existing tax incentives for scientific and technological talents still need to be improved, and the effective tax incentive mechanism for innovative talents has not yet been formed. In particular, the individual income tax incentives for high-end highquality talents still need to be supplemented and improved. For example, with respect to individual income tax, an individual is exempted only if he has received an award in environmental protection, health, technology, sports, culture or science from an international organization, a people's government at or above the provincial level, or if he has received a special government allowance in accordance with national regulations. As for the scientific and technological progress and major achievements awarded by enterprises to individuals, personal income tax is still taxed.

\section{Suggestions}

\subsection{Strengthen policy publicity}

To implement various policies, we must strengthen policy propaganda. Although many enterprises, especially small and medium-sized enterprises, are pioneers of innovation, they lack relevant knowledge and do not understand or even understand the newly issued tax-related policies. Under such circumstances, government departments and taxation authorities at all levels must enhance their service awareness, actively promote and guide enterprises to conduct scientific research and development, and regularly train enterprise accounting personnel to increase their awareness of taxation policies and maximize their effectiveness.

\subsection{Relaxation of preferential restrictions and refine policies and regulations}

Even if many companies have a lot of R\&D investment and understand preferential policies, they cannot enjoy tax incentives because they do not meet the preferential conditions. If we want more products to switch from "Made in China" to "Created in China", we must appropriately lower the conditions for enterprises to enjoy tax incentives. For example, the qualifications for "hightech enterprises" can be appropriately relaxed, so that more enterprises can enjoy the benefits of preferential tax policies and promote the transformation and upgrading of enterprises. On the one hand, the financial staff of the enterprise must fully understand the tax policy. On the other hand, some items should be refined, and some clauses that are not clear enough can be supplemented. It 
is also necessary to introduce corresponding policies as soon as possible in response to new and emerging situations.

\subsection{Promote and improve the anti-risk ability of enterprises as an innovation subject}

When banks loan funds to SMEs as R\&D investment, interest can be recorded at low interest rates, and interest can be taxed at preferential tax rates. Venture capital companies investing in small and medium-sized technology companies transferred after listing may be exempted from VAT on equity transfer. It is further clarified that in the "proportion of income from high-tech products (services) to the company's total income for the year", incidental factors such as equity transfer income are not included in the total income for calculating the proportion of high-tech income. At the same time, the income from technical services, technology transfer, technology development and other services will be compared with the policy of immediate refund of software products, and the excess tax burden will be refunded to support the development of high-tech enterprises.

\subsection{Build a tax data platform}

Tax authorities can make full use of big data, cloud computing, Internet of Things and other information technologies to integrate corporate information, tax information, industrial and commercial information, banking information, insurance information, patent office information, etc., to build big data platform, full of information communication, to simplify and merge the redundant tax links, optimize the tax business process, for the smooth implementation of the tax policy to build a good environment, put an end to some enterprises to tax evasion and tax avoidance. At the same time, tax authorities can analyze data in real time, evaluate policy effects, find deviations in the policy implementation process, and process and analyze deviations to provide strong guarantee and support for the development of scientific and technological innovation of enterprises.

\section{Conclusion}

In the context of big data, independent innovation is a key link to promote economic restructuring and the transformation of growth mode, and is the core driving force for achieving sustained, coordinated and rapid social and economic development. Taxation is a lever for the government to regulate the economy, and it is naturally a scientific choice of the government to use taxation policies to promote the development of independent innovation of Chinese enterprises.

\section{References}

1. Zhai Guannan. Research on taxation policies to encourage independent innovation of enterprises [D]. Capital University of Economics and Business, 2016.
2. House Lei. Research on the path of dynamic teaching of tax law courses in vocational colleges under the normal reform $[\mathrm{J}]$. Newsletter of Vocational Education, 2019(14):52-55.

3. Jiang Jun, Liu Can. Comparative analysis of R\&D expenditure and scientific research output of major countries (regions) in the world[J]. National Science Foundation of China, 2020,34(03):367-372.

4. WIPO. WIPO IP Statistics Data Center. https://www3. wipo. int/ipstats/index. htm

5. Li Hua. Research on the impact of tax incentives and adjustment costs on corporate R\&D investment behavior [J]. Contemporary Finance, 2018(07): 25-34.

6. Research Group of Wuhan International Taxation Research Association, Chen Yufang, Liu Dan, Liu Jing. Comparative study on taxation policies for encouraging enterprises' scientific and technological innovation[J]. International Taxation, 2018(04): 7175 . 